\title{
Head of Polish society of Virology
}

\author{
Małgorzata Polz-Dacewicz' \\ ${ }^{1}$ Department of Virology, Medical University of Lublin \\ Polz-Dacewicz M. Head of Polish society of Virology. J Pre-Clin Clin Res. 2013; 7(2): 69-70.
}

\section{INTRODUCTION}

Viral diseases have been known since antiquity. The first descriptions of symptoms typical for poliomyelitis derive from excavations in Memphis, $20 \mathrm{~km}$ south of Cairo in Egypt. They are dated to about $1400 \mathrm{BC}$. Even then, attempts were being made to identify diseases and prevent them. The first trials of vaccination against smallpox began before 1000 $\mathrm{BC}$ in China where the disease occurred endemically. The development of bacteriology, however, could not explain the cause of many infectious diseases; neither Louis Pasteur nor Robert Koch could distinguish bacteria and viruses as two separate types of germs, despite extensive work on rabies and creating a vaccine against this disease.

Dmitri Ivanovski's tests had great importance in demonstrating the existence of a new pathogen separate from bacteria. In 1892, he discovered the presence of an infectious agent causing the mosaic disease of tobacco plants, which he thought was a toxin produced by bacteria. In 1898, Martinus Beijerinck conducted similar research, but he suggested that this was a new form of infectious agent and called it a contagium vivum fluidum. However, it was not until 1935, thirty-seven years later, that the American biochemist and virologist Wendell Meredith Stanle described the molecular structure of the tobacco mosaic virus, demonstrating that it had properties of both living and non-living matter. This was the first virus to be thoroughly analysed.

In 1898 , the same year as Beijerinck carried out his research on the tobacco mosaic virus, Loeffler and Frosch discovered the first animal virus-agent of foot-and-mouth disease (aphthovirus).

In 1909, Karl Landsteiner and Edward Popper proved that filterable germs cause poliomyelitis. Bacteriophages (viruses infecting bacteria) were discovered in 1915 by Frederick Twort, and two years later, Felix d'Herelle confirmed their existence.

By the end of the nineteenth century, viruses were defined on the basis of their infectivity, and ability to pass through bacterial filters and multiply in living organisms. Viruses had been multiplied only in the plant or animal organisms. In 1906, Ross Granville Harrison applied the method of tissue culture. Thanks to his work, Steinhardt, Israeli and Lambert used this method in 1913 to propagate pox virus in fragments of tissue from the cornea of guinea pig. This was important for the expansion of research on the nature of viruses. This method allows for the possibility to obtain high titer of virus and allows studying the transcription and translation of the viral genome.

The next significant step in the development of virology was the invention in 1931 of an electron microscope by

Address for correspondence: Małgorzata Polz-Dacewicz, Department of Virology, Medical University of Lublin, Chodźki 1, 20-629 Lublin, Poland

e-mail: malgorzatapolzdacewicz@umlub.pl

Received: 05 February 2014; accepted: 15 February 2014 the German engineers Ernst Ruska and Max Knoll, which gave the opportunity to gather more information about the morphology of viruses. The subsequent years were a rapid period of time for the development of virology, this narrow specialization which has only recently became one of the most important sectors of the biological sciences, and has been important in general biology, medical, veterinary and agricultural sciences. Fundamental biological processes (such as the genetic code issues, synthesis of nucleic acids and proteins, chemical mutagenesis) are tested on the viruses model.

The twentieth century was a time of discovery of new viruses, such as influenza and poliomyelitis. Anthony Epstein, Yvonne Barr and Bert Achong described the latter virus which is called the Epstein-Barr virus. This fact is important for the history of virology because it was the first human oncogenic virus. During the second half of the twentieth century, called the golden age of virology, about another 2,000 species of viruses present in animals, plants and bacteria (bacteriophages) were discovered. In 1963, the hepatitis B virus was discovered by Baruch Blumberg, and in 1965, Howard Temin described the first retrovirus. In 1970, Howard Temin and Davin Baltimore were the first researchers who found reverse transcriptase, the enzyme that retroviruses use to make DNA copies of their RNA. It was a great importance for the development of antiviral drugs. This fact was a turning point in the history of virology. In 1983, Luc Montagnier and his team from Pasteur Institute isolated the retrovirus which is now called HIV. The twentyfirst century has brought the discovery of new viruses such as SARS and Nipah.

The development of microbiological and immunological science in the twentieth century, the introduction of a number of vaccines and new drugs, suggested belief that infectious diseases would soon cease to threaten the world. In 1980, smallpox was been eliminated from all countries worldwide. The two banks with the strains of the virus shut down production of the vaccine, but today we have a huge population of people fully susceptible to smallpox infection. Many epidemiologists wonder if we are able to be effectively prepared in the event of an epidemic of smallpox. Many people thought that infectious diseases (or at least many of them) have gone down in history. Unfortunately, these misconceptions were quickly verified by new cases of old diseases.

The epoch of globalization, progress and development of civilization expressed by increasing population density, migration, and the rapid movement of populations represents a significant threat of viral diseases. There are new dangerous viral diseases like Acquired Immunodeficiency Syndrome (AIDS), Severe Acute Respiratory Syndrome (SARS), avian flu or swine flu. We have to reckon with the possibility of the emergence of the next unknown viral diseases. In 2012, the International Committee on Taxonomy of Viruses registered 
2,480 virus species classified in 395 genera, 22 subfamilies, 94 families and 6 orders. Not without significance is the increase in the number of immunocompromised patients with a high risk infections, including those of viral etiology. A significant number of patients with chronic hepatitis B and $C$ require antiviral treatment. High mutability viruses cause the selection of strains resistant to chemotherapeutic medications used in viral diseases. On the other hand, we have a relatively small number of virucidal activity drugs, usually with a narrow spectrum and low specificity which are generally characterized by high toxicity. All of these factors are the reason for incessant studies on the search for new antiviral drugs that act at different stages of the virus replication cycle. Research is directed at obtaining drugs by de novo chemical synthesis. The second way is searching for natural compounds, of either vegetable or animal origin, in order to create their synthetic derivatives.

Demographic changes, behavioural changes, on the one hand, and on the other hand changes in the environment (ecosystem, climate, urbanization, deforestation, development of industry and technology) favour the spread of old and new pathogens. An important factor is the change in virulence of virus, the selection of strains resistant to currently used antiviral drugs and even disinfectants. Viral diseases of fish, birds, mammals, and viral infections of arable crops are causing major economic losses. For this reason, in the era of globalization, coordination at regional, national and international levels is necessary. Virological societies operating in different countries are trying to address these challenges. The Polish Society of Virological has been in operation since 2010.

On 19 - 22 June 2013, the IIIrd Virology Days took place in Lublin, during which the First Congress of the Polish Society of Virology was held. The Congress was carried out under the honorary patronage of His Magnificence the Rector of the Medical University of Lublin - Prof. Andrzej Drop.

The Chairman of the Polish Society of Virology -Prof. Małgorzata Polz-Dacewicz - received many congratulatory letters on the occasion of First Congress. Krzysztof Chlebus, Under-Secretary of State at the Ministry of Health, wrote in his letter: "... Please accept my compliments and congratulations for your actions in the field of science - virology ...". Edyta Kramek, Deputy Director of the Department of Science and Higher Education at the Ministry of Health, wrote: "Please accept the expression of appreciation for the initiative to establish the Polish Society of Virology by Mrs. Polz-Dacewicz. Virology is the science characterised by a rich history and achievements. However, still new diseases of unknown etiology are emerging, causing serious threats to public health security in the world. I strongly emphasize the importance of this initiative which will also directly affect the health safety of Poles ... I hope that the Congress of the Polish Society of Virology will be the basis for the development of many scientific and research groups aimed at virological problems, and it will help towards the contribution of Polish science in the growth of this important sector of knowledge." Prof. Bolesław Samoliński, National Consultant for Public Health, wrote: "Virological problems are very important for the health of the population, and therefore fall within broadly defined public health. For this reason, I, as a National Consultant in this area, feel a great responsibility, together with the Association of Virologists, which in cooperation with other specialists (including specialists in public health) can have a significant impact on health security in Poland."

Due to the dynamic development of the scientific discipline which virology has undoubtedly become, the Journal of Preclinical and Clinical Research has created a new section - 'Clinical Virology' - where a large group of virologists can publish the results of their research. 